\title{
Domestic Extremist Criminal Damage Events: Behaving Like Criminals or Terrorists?
}

\begin{abstract}
Property damage is a ubiquitous criminal direct action tactic perpetrated by left-wing extremists in Bristol to advance a variety of causes, yet it remains understudied. This study uniquely contributes to the field by analysing the selection of targets for property damage by left-wing extremists in the British town of Bristol. Using police data and online claims of responsibility, this study analyses a number of situational factors providing guardianship at the target locations of 95 Domestic Extremism incidents and compares them with 95 conventional property damage incidents. The results suggest that left-wing extremists do not behave in the same manner as conventional criminals as they fail to conform to theoretical expectations regarding the effect of guardianship on target selection decisions. Instead, Domestic Extremists appear to adhere to decision-making schemas more commonly associated with terrorists. This raises important questions about the relevance and usefulness of these theoretical frameworks for understanding Domestic Extremism.
\end{abstract}

Key words:

Direct Action, Property Damage, Left Wing Extremism, Domestic Extremism, Situational Crime Prevention 


\section{Introduction}

Over the past few years, media reports highlighted a growth in left-wing inspired acts of criminal damage and arson in the British town of Bristol (Morris, 2015). Official U.K. policy treats the offenders involved as 'domestic extremists' (hereafter, DE), defined as “individuals or campaign groups that carry out criminal acts of direct action in furtherance of what is typically seen as a single-issue campaign." (HMIC, 2012). A dedicated National Domestic Extremism and Disorder Intelligence Unit (NDEDIU) ${ }^{1}$ exists. However, as it is deemed these activities pose little threat to national security they are often dealt with by local police 'Special Branches' as opposed to UK security services such as MI5 (MI5, 2013).

Localised activities of DE typically consist of activities (such as the destruction of property) that would constitute offences under the U.K.'s Criminal Damage Act 1971, and fall under a broad DE strategy of 'direct action'. This strategy is designed to cause operational difficulties, damage to reputation, and/or financial losses for the target. By exerting such pressure, the aim is to coerce companies/agencies into changing their policies or addressing perceived political, social or environmental injustices (Doherty et al, 2003, Staniforth, 2009; Wall, 1999). The destruction of property is widely used as a direct action tactic as it is non-violent, and therefore considered as acceptable to DE activists (Borum and Tilby, 2005; Franks, 2003; Doherty et al, 2003).

This paper seeks to identify whether DE criminal damage events are like non-DE criminal damage events. We examine the influence of situational factors, i.e. the presence of security features, such as closed circuit television (CCTV) and fencing, differ across offender types when examining property damage offences. Using police data and online claims of responsibility, this study quantitatively analyses the target locations of 95 'direct action' property damage incidents by left-wing extremists in Bristol. We compare these crimes with 95 conventional property damage incidents in the same area, to identify ways in which they differ. The results suggest that DEs committing direct action attacks are dissimilar to conventional criminals as they are less likely to conform to theoretical expectations regarding the effect of guardianship on target selection decisions.

\footnotetext{
${ }^{1}$ In the United States (U.S.) domestic extremism is dealt with under the Department of Homeland Security, alongside other forms of terrorism (Young, 2002; Garrett, 2004, Clarke and Newman, 2006; US Department of Homeland Security, 2009; 2018).
} 


\section{Theory}

The rational choice perspective on offending in volume crimes is long established, with research consistently demonstrating that criminal offenders are rational actors. Criminals make evaluations and judgements about a given situation that inform their decision to commit a crime at a given point in time. Decision making is strongly influenced by the situational factors encountered in the immediate environment at the point of crime, as well as a consideration of past experiences and existing behavioural repertoires (Cornish and Clarke, 2008; Felson and Boba, 2010). This means that situational factors such as perceived level of guardianship at a site may act as a control mechanism to discourage crime (Brantingham and Brantingham, 2008).

Criminal decision making is conceptualised in terms of a rational cost-benefit analysis where risk, effort and reward are considered (Brantingham and Brantingham, 2008; Clarke, 2008; Cornish and Clarke, 2008). There is almost always an element of uncertainty in decision making, as the available information needed to make a decision is often incomplete (Roach et al., 2005). It is only possible for criminals to consider a limited number of factors at any given point: "decision-making (...) will tend to concentrate solely on those situational factors that hinder or advance instrumental action in fulfilment of the criminal goal" (Cornish and Clarke, 2008: 31).

Like other extremist events, direct action acts committed by UK DEs are used to convey a message. As such, the offenders may have a limited choice set of targets that will be relevant to their ideology to choose from. Nevertheless, their decision making regarding the selection of a target within this choice set of symbolic targets will still be guided by an inherent logic. Gill et al (2018) found that extremists tend to consider several potential targets before selecting the one with the fewest associated risks. Rational considerations of risk and the related impact on decision making have been exhibited in claims of responsibility. In November 2013, the left-wing extremist group FAI/Improvised Guerrilla Formation posted a claim of responsibility online for a direct action attack against a bank branch of one of the major UK banking groups. Banks are often targeted by left-wing groups as they can be considered symbolic of capitalism. One section of FAI's claim summarizes the reasons for attacking the banking group, such as it being "the largest global investor in the arms trade"; "the largest institutional shareholder in [a] notorious animal-torturing group"; and "possibly the largest capitalist-industrial investment 
project on Earth and cause of the second-fastest rate of deforestation on the planet". Another outlines the relative attractiveness of the specific target chosen, from an operational perspective. This deliberation demonstrates offender awareness of the crime environment, and a consideration of situational factors. In this case, it is clear that the offender's awareness of risk associated with the site explicitly informed decision making for target selection:

"The bank branch was chosen for its lack of adjacent buildings, and to avoid the extremely low chance of passers-by in the area we positioned the device against the back of the building against a window, instead of multiple devices on opposite sides as is commonly recommended."

The 2009 National Counter Terrorism Security Office ${ }^{2}$ advice booklet for businesses 'Beyond Lawful Protest: Protecting Against Domestic Extremism' recommends several crime prevention measures to deter, detect and delay offenders. Central to the guidelines provided is the role of guardianship provided by security guards and employees in addition to other physical security measures. Good lighting, CCTV, perimeter fencing, as well as removal of exterior planting that obscures surveillance of a potential target are all advised as protective measures. The opportunity to commit crime depends on finding a suitable target that is insufficiently guarded (Roach et al., 2005), as the presence of situational factors providing guardianship increases the risk of apprehension. Hollis et al (2013: 66) are strong advocates for the effects of guardianship: "the most important mechanism involved is the feeling that someone is watching and could observe inappropriate behaviours thus increasing the risk". The criminal's perception of a situation and how this relates to their decision to commit the crime is essential. Therefore, it logically makes sense that proxy measures such as CCTV (whether manned or otherwise) or factors that make it more likely that a guardian will observe the crime should be incorporated within the concept of 'guardianship'. These levels of guardianship indicate an increased amount of risk alluding to risk of apprehension, increasing fear in the offender.

Wilcox et al (2007) consider four dimensions of guardianship from individual through to neighbourhood-wide efforts including formal and informal control, as well as non-human protection devices ('physical guardianship'). They acknowledge that some factors that may be

\footnotetext{
${ }^{2}$ The National Counter Terrorism Security Office (NaCTSO) is part of the Association of Chief Police Officers (ACPO). It supports the Protect and Prepare strands of the UK counter terrorism strategy (CONTEST).
} 
seen as 'hardening' overlap with guardianship, for example burglar alarms, as well as those improving natural surveillance such as street layout and absence of tall shrubs and fences. They found that the aggregate effects of multi-dimensional guardianship were most effective in reducing crime.

When considering their motivations and expectations, such as extreme political ideologies, it has often been proposed that extremists must be irrational decision makers. However, research consistently suggests rational thinking in the planning, preparation and commission stages of an offence (Schuurman et al., 2018; Gill et al., 2018; Marchment et al., 2018). Clarke and Newman (2006) assert the motivational differences between criminal and terrorist offending are not so marked and are of marginal importance for situational prevention, as opportunity is key to target selection. Caplan (2006) uses 'rational irrationality' to describe terrorist decisionmaking. He proposes that terrorists are willing to adopt riskier tactics because they are more effective and the odds of achieving their desired outcome of sending a message are higher.

The lack of an ideological basis guiding non-DE criminal damage events means that they may be taking different factors into consideration when selecting targets. For DEs, the selected targets are more likely to be of a symbolic nature, relevant to their ideology. Therefore, committing acts in more 'public' places may be necessary, and carried out regardless of SCP measures. They may believe the associated risk is outweighed by potential rewards. We therefore hypothesise the following:

H1: There will be a difference in prevalence in guardianship factors in the locations of DE criminal damage attacks and non-DE criminal damage attacks.

Next, we consider a range of situational factors providing guardianship of a target, including environmental features improving natural surveillance, as well as informal and formal surveillance.

\section{Situational Factors}

Welsh et al (2010) describe guardianship in terms of the presence of formal, informal and natural surveillance. Formal surveillance includes security guards or physical security measures such as CCTV. Informal surveillance includes 'place managers', whereas factors 
such as street lighting or proximity to a heavily transited arterial route assist natural surveillance by persons engaged in routine activities. Cornish and Clarke (2003, in Welsh et al., 2010) argue that these factors correlate with lower crime rates as crimes are perceived as riskier and therefore less attractive when weighed up against potential benefits.

Newton and Bowers (2007) examined environmental factors and their correlation with bus shelter damage. They found a lack of capable guardianship and 'open space' were key factors and suggest future research should include further factors such as natural surveillance and lighting levels. This is supported by Tewkesbury and Mustaine (2000) who found increased vandalism victimisation rates for those living near parklands with minimal amounts of supervision and control. Targets that are not overlooked or that are isolated may be perceived as less risky, due to reduced surveillance by guardians. It should therefore hold that the opposite is true for targets close to arterial routes or those that are highly visible. It is therefore hypothesized:

H2: DE criminal damage attack locations are more likely to have a capable guardian present than non-DE criminal damage events

H3: DE criminal damage attack locations are more likely to have lighting present than non-DE criminal damage events

CCTV increases the perceived risk of being apprehended (Wilcox et al, 2007; Hollis-Peel et al., 2011; Hollis et al., 2013). Although it is a proxy measure, the fact that the guardianship it confers explicitly informs decision making for target selection is evidenced in a claim of responsibility for criminal damage posted on Indymedia UK website:

"This was just a small token for the distaste felt for being constantly watched, that so many people vocalise, but ultimately feel powerless to act,. [sic] There will be more actions like this so keep your eyes open, a view to a thrill, you'd think day-time in the city \& cctv they'd have our lives sewn-up........not so, Still [sic] chucking rocks in the free world.” (Anonymous ${ }^{\text {a }}$, 2013).

We therefore hypothesize:

H4: DE criminal damage attack locations are more likely to have CCTV present than non-DE criminal damage events 
Physical structures such as fencing also increase the effort required to access a target. The presence of such features inevitably means physical exertion to scale the fence or a need to damage it to enter the enclosed area. These factors can increase the perceived risk of being detected as this may attract unwanted attention. We hypothesize:

H5: DE criminal damage attack locations are more likely to have fencing present than non-DE criminal damage events

Related to this, target visibility has a similar effect on perceived risk levels as it also increases exposure to surveillance (Brantingham and Brantingham, 2008; Clarke, 2008; Cornish and Clarke, 2008; Von Lampe, 2011; Hollis et al., 2013). It may be conferred by architectural or environmental features, or due to the prominent nature of the target itself. It is obvious that iconic or well known targets, such as liveried vehicles, or civic, commercial and public buildings which are typically situated in conspicuous locations, are inherently subject to high levels of guardianship.

H6: The targets of DE criminal damage attacks are more likely to be publicly visible than the targets of non-DE criminal damage events

In a similar manner, criminal decisions regarding the modus operandi of an offence will be made in response to situational factors. Depending on the offence type, the effort involved and the perceived risks of detection will vary (Brantingham and Brantingham, 2008; Clarke, 2008; Cornish and Clarke, 2008; Von Lampe, 2011; Hollis et al., 2013). For example, whether property damage is carried out simply using bodily force or involves more complex direct action strategies utilising instruments such as paint, fire lighters or sharp implements (Borum and Tilby, 2005) may determine how likely the offenders are to come to the notice of guardians.

H7: DE criminal damage attacks are more likely to necessitate the use of an instrument than non-DE criminal damage events

\section{Data \& Methodology}

Two websites used by DEs to post responsibility claims for criminal direct action provided the first point of reference for sampling: www.bristolindymedia.org and www.325.nostate.net. We 
identified all claimed incidents between January 2010 and January 2014 from postcode districts covering the Bristol area that adhered to the legal definitions of criminal damage and arson. These incidents were then cross-referenced against police crime reports to (a) verify the incident occurred and (b) to ensure that adequate information was accessible for analysis. Most incidents had been reported to the police and were therefore included in the sample. We then selected a control group of non-DE criminal damage events from police records spanning the same time period. The 'Research Randomizer'3 web-based random selection tool chose the 95 non-DE incidents. Figure 1 depicts the full sampling framework.

Avon and Somerset Constabulary granted the access and use of all stated crime report data. Police crime records provided information about a variety of situational factors as determined by investigative norms. Google Earth and Street-View, as well as information derived from the 2011 Office for National Statistics Census (ONS) supplemented this information. To preserve victim confidentiality it was not possible to visit target locations.

\section{[Insert Figure 1]}

The dependent variable was whether the incident was a DE related incident. The independent variables relate to situational factors providing guardianship at a target location, and were as follows: the presence of (a) capable guardians, (b) fencing, (c) lighting and (d) CCTV; the degree of target visibility; the target type (public/private building); whether the crime involved the use of an instrument; and the offence type (criminal damage/arson). Multiple incidents occurring simultaneously at the same target location were only counted once within the data set to prevent distorted results.

As it is impossible to isolate the situational factors considered in each case by the perpetrator, and to ensure reliability and validity, only factors with data availability across the entire sample were selected as independent variables. Binary indicator variables were used for all variables. The variable capable guardian present was based upon both informal and formal surveillance, with 'presence' indicating if the incident was witnessed or mention was made of presence in the crime report, for example a security guard or staff member. This is not to say that when

\footnotetext{
${ }^{3}$ The 'Research Randomizer' random sampling and assignment tool is available from: http://www.randomizer.org/
} 
such information was absent from crime reports that no guardians were present, however there is no way of measuring this hence the reliance on crime report information.

Each observation was coded for the presence of the following features: fencing, lighting and $C C T V$. The variable regarding whether the target is publicly visible or not was determined using Google Maps' satellite view. The proximity of the target to thoroughfares/main arterial routes was ascertained using the 'scalar' key. If the target was within 20 feet/10 metres then it was coded as visible. Whether an instrument (i.e. paint, fire-lighters, sharp implements etc.) was used to commit the crime, (as opposed to the property damage being carried out simply using bodily force) was determined using the police casefiles.

Data analysis consisted of both bivariate and multivariate analyses. First, chi square analyses were conducted. Those variables with values of $p>0.05$ were deselected and dropped from the binary logistic regression. This left seven independent variables for the binary logistic regression.

\section{Results}

The sample size was $n=190$, with 95 cases allocated to each group (DE, non-DE), with a description of cases presented in table 1.

Table 1.

\begin{tabular}{|l|l|l|}
\hline & DE & Non-DE \\
\hline Arson & 27 & 28 \\
\hline Criminal Damage & 68 & 67 \\
\hline Total & 95 & 95 \\
\hline
\end{tabular}

\section{Bivariate Analysis}

Chi-square analyses were conducted on all independent variables, to see whether their presence was more likely at DE events when compared to non-DE events. Table 2 includes those that displayed significant results.

[Table 2 Here]

The results show some differences with respect to the presence of guardianship factors at DE and non-DE criminal damage locations, thus confirming H1. Capable guardians and lighting 
were significantly more likely at non-DE extremist events. Non-DE targets were also significantly more likely to be publicly visible. DE event locations were significantly more likely to have fencing and CCTV present. The results also indicate that DE events are more likely to target commercial/public/state buildings. DE attacks were significantly more likely to involve the use of an instrument.

\section{Multivariate Analysis}

A binary logistic regression analysis showed that in combination, the independent variables significantly impacted on the likelihood of the perpetration of criminal damage and arson incidents by DEs $\left(\chi^{2}(7)=158.855, \mathrm{p}<0.001\right)$ and the model correctly predicted $88.4 \%$ of the cases. Several individual variables were significant predictors of the occurrence of DE incidents. The presence of lighting and CCTV, the use of an instrument, and the target being a public building were all significantly associated with DE events. The presence of a capable guardian, the visibility of the target, and the presence of fencing all possessed non-significant values.

[Table 3 Here]

\section{Discussion and Conclusion}

The purpose of this study was to analyse differences in existent situational factors providing guardianship at target locations for property damage by DEs in Bristol. DEs appeared to be less concerned about the elevated risk levels associated with the presence of factors providing guardianship at target locations. The results suggest that situational factors expected to act as deterrents for crime are not as strong for extremist events.

Consistent with our first hypothesis, there was a contrast between the behaviour of the control group of non-DE related events and DEs. The logistic regression analysis showed that the perceived presence of a capable guardian did not have a significant effect on target selection compared to the non-DE sample. However, the presence of lighting and CCTV at a target location were significantly associated with DE events. It can be inferred that these factors are less of a deterrent for those engaging in DE criminal activity. This is supported by a DE statement below that demonstrates an awareness of the presence of factors providing guardianship and an acceptance of the risk they perceive: 
"This was despite of the still increasing number of high quality security cameras along that stretch of road and the surrounding area, and despite of the fact that those involved knew it was a well used police route" (Anonymous ${ }^{\mathrm{b}}, 2011$ ).

The bivariate results showed that DE criminal damage events were more likely to occur in places where fencing was present. The regression results additionally indicate that, as DE criminal damage events were significantly more likely to occur in public places when compared with non-DE criminal damage events. Further dimensions should be added to existing measures at these sites, to prevent or disrupt extremist activity, and it should not be assumed that existing protective measures will be successful for DE related activity.

The different locations in which criminal damage offences plays could be indicative of a different behavioural underpinning. The lack of an ideological basis guiding non-DE criminal damage events means that they may be taking different factors into consideration when selecting targets. For DEs, where the selected targets are more likely to be of a symbolic nature, they may believe the potential rewards are worth the associated risks. It is possible that out of many similar targets, i.e. a few different branches of the same bank, that the one that was selected was perceived as the least risky, or the most convenient. Within an urban environment there may be several subsidiaries of a given company or organisation or target that could potentially act as a target vector for a cause. Some of these subsidiaries may contain a greater number of guardianship factors and so the site eventually targeted may be the most rational site given the discrete choices at the disposal of the extremists. Without a consideration of all the potential targets that could have been chosen we cannot fully explain the importance (or lack thereof) of guardianship factors in the targeting decisions of left-wing extremists. This needs to be explored further in future research, using alternate methods such as discrete choice modelling. This approach allows locations that were chosen and locations that could have been chosen but were not to be examined simultaneously.

Fussey (2011) highlights how the use of measures such as CCTV to increase guardianship levels and perceived risk, although widely advocated, is misguided. Although CCTV is specifically recommended as a measure to protect against DE (NaCTSO, 2009), the results support Fussey's view. It suggests that DEs are more likely to attack a target with CCTV, which may be related to the fact that desirable commercial, state or public building targets which would be expected to have CCTV had higher odds of being attacked. This ties in with Caplan's 
(2006) conceptualisation of terrorist decision-making as it demonstrates an acceptance of riskier tactics. This is associated with the importance of symbolism related to the ideology underpinning an attack, including deliberate selection of hard targets such as the targeting of the state by left-wing terrorists to prove a point (Fussey, 2011). The DEs offer further evidence that they are willing to attack riskier targets despite the presence of guardianship factors for ideological reasons:

"We refuse to wait for the next big event to act. We believe in acting without hesitation, in seizing the initiative and striking where and when we want. The state cannot be everywhere, and with preparation and precautions these actions are simple and relatively safe, though of course not without risks we willingly take." (Anonymous , 2011)

The results indicate a need for immediate change in the law enforcement response to DE. Deterrents for conventional crimes may not be as effective for DE-related activity. Specialist knowledge is required to ensure full understanding of this complex phenomenon, thereby facilitating responsive approaches to the problem of preventing DE attacks. Although most property damage is regarded as relatively minor, the fact that DEs are so forensically aware justifies the use of resources more in line with serious crime to improve detection rates, for example scene preservation to maximise evidential recovery opportunities. Prevention opportunities are associated with the planning and preparation undertaken by DEs, including hostile reconnaissance (Staniforth, 2009) and the use of instruments to commit property damage indicated by the analysis. By raising awareness of DE and associated tactics, this may increase public vigilance thus improving guardianship, and may promote improved use of police powers such as 'stop and search'.

Official policies are in need of change to embrace motivational factors and the wealth of available terrorism research as part of a more holistic and nuanced understanding of the phenomena, rather than adopting a simplistic but ineffective approach to DE. The fact that DE is not specifically included in the Terrorism Act 2000 (ACPO, 2013) even though in certain circumstances this legislation could encompass DE incidents must be reconsidered; this is also the case regarding the lack of a legal definition of DE due to the current view that there is provision in other areas of legislation (www.acpo.police.uk, 2013). By reconceptualising DE as terrorism rather than conventional crime, with the improved understanding and resourcing that would accompany this, UK security and law enforcement agencies would be better equipped to approach DE crime prevention and detection. 
According to opportunity theories, target selection involves an objective decision made in response to the immediate environmental conditions at a particular point in time and space (Brantingham and Brantingham, 2008). This is not necessarily the case with DE; resourceful offenders identify opportunities through planning and searching rather than accidentally whilst engaged in routine activities (Von Lampe, 2011). There is therefore commonality with terrorist decision-making as well as practices including networking, training, hostile reconnaissance, and operational planning and preparation (Fussey, 2011).

Certainly, DEs are known to conduct reconnaissance and research of suitable targets including situational conditions at a target setting (Staniforth, 2009). DE decision making schemas are also influenced by specific training. The Anarchist Black Cross Federation offers training in activism, direct action tactics as well as counter-surveillance, forensics and policing tactics to avoid apprehension (Borum and Tilby, 2005). Training has made activists forensically aware (Garrett, 2004). This may explain why DEs willingly attack targets despite guardianship factors. Planning and preparation includes tactics that mitigate the risk of being seen, thereby allowing them to attack their preferred targets, as well as showing a level of sophistication that is commensurate with terrorism:

"Remember to always practice safe sex

Wear a mask/balaclava according to the manufacturers specifications and guidelines Or scarf-up over face and wear gloves for an unforgettable penetration".

(Anonymous $\left.^{\mathrm{d}}, 2014: 24\right)$

This could be an indicator of criminal adaptation: the process in which individual offenders circumvent preventative measures over time (Clarke, 2013); this indicates a requirement for responsive approaches to the problem of preventing DE attacks. Certainly, some contemporary anarchist thinkers embrace terrorism as a revolutionary instrument, extolling the actions of the Unabomber and criticising 'Green yuppies' and all other 'anarchists' who do not participate in criminal direct action (Zerzan, 2002, in Kinna, 2005). The clear influence of such thinkers upon the DEs examined for this study and their self-identification with terrorism is evidenced in an anonymous NoState325 website posting: 
'(...) we don't have to reinvent the wheel, we can be critical and like a rap-artist, take samples (ideas) we've stolen from the Angry Brigade, IRA, PLO, Red Army Faction and the Unabomber.' (Anonymous ${ }^{\mathrm{d}}, 2014: 5$ )

A number of limitations exist in this study. The focus on data for the Bristol area imposes analytical restrictions due to sample size and affects the generalizability and reliability of results. Bristol may be a unique case. The city is characterised by left wing political sympathies and activism for a variety of causes. As Purdue et al. (2004: 278) assert: "Bristol has a reputation for new social movement activity and a strong community and voluntary sector", characterised by a milieu of entrepreneurism, liberalism and anarchism. This environment is conducive to direct action and although the majority of such activity is legitimate and lawful, numerous property damage incidents have been perpetrated by DEs across Bristol ${ }^{4}$. Indeed, Diani (2005) recognises the level of activism and direct action in Bristol as being of national significance. Furthermore, it is recognised that using secondary data sources, especially official data sources can be problematic (Bryman, 2008). As only incidents reported to police were included in the sample, this may have excluded some relevant data. In addition, as data was collected for policing purposes it may be influenced by recording practices, as well as what information individual officers recorded as part of their investigation (LaGrange, 1999; Hox and Boeije, 2005). Not only does this limit the choice of valid independent variables available for analysis, but it may also affect the validity of the conclusions drawn by this research.

One issue encountered across both sample groups was the nature of available temporal data. Although it was possible to identify the day of the week that incidents occurred, the volume of wide timeframes recorded meant that analysis of time that incidents occurred would have been meaningless and invalid. Therefore, the decision was made to exclude these variables.

There are also limitations associated with using DE responsibility claims. Their validity or accuracy cannot always be judged (Gordon, 2007). Efforts have been made to ensure that crimes claimed did actually occur through cross referencing with crime reports, but this does not mean that those claiming responsibility actually perpetrated the crime. It is possible that not all DE offences were identified if they were not claimed online.

Also of interest is that several incidents (12) occurred under special circumstances, the majority of which were control group cases. These included domestic violence, a prisoner damaging a

\footnotetext{
${ }^{4}$ This study analyses $n=95$ DE property damage incidents over 4 years.
} 
police cell and incidents with ancillary property damage. There was only one such DE case, which took place during the Bristol riots. Certainly, these incidents occurred under unusual circumstances and may introduce bias into the results. Nonetheless, the control group sample was chosen at random and as such should be broadly representative of the population it represents so would naturally incorporate such incidents.

Finally, as consideration of every possible factor present is beyond the scope of this study, there may be unobserved variables that are impossible to control for, including any natural variation between place attributes for each location. Nevertheless, it is important to note that in reality criminals decisions are not perfect and not all situational factors would be considered, so this does reflect reality in this sense (Cornish and Clarke, 2008).

This study demonstrated that differences occur in the way crimes involving damage to property are conducted, which are reflective of the motivation of the crime itself. The results demonstrated that variables associated with guardianship appear less relevant in the DE sample. There is a clear need for further study of this phenomenon. Larger scale studies could encompass more data, overcome analytical restrictions and improve the generalizability and reliability of results. There is also scope for comparative research to provide further insights into local variations and a requirement for development and testing of new models to address the aforementioned theoretical problems. 


\section{References}

ACPO (2013) NCDE National Co-ordinator Domestic Extremism [WWW] Association of Chief Police Officers (ACPO). Available from: http://www.acpo.police.uk/NationalPolicing/NCDENationalCoordinatorDomesticExtremsim. html [Accessed 05/10/13].

Allison, Paul (2004) Convergence problems in logistic regression. In: Altman, Micah, Gill, Jeff and McDonald, Michael P. (eds.) Numerical Issues in Statistical Computing for the Social Scientist. New York: Wiley, pp.219-233.

Anonymous (2013) Bristol city council mobile cctv vans attacked [WWW] Indymedia UK. Available from: http://www.indymedia.org.uk/en/2013/12/514042.html [Accessed 30/08/13].

Anonymous $^{\mathrm{b}}$ (2011) Banks smashed in Bristol [WWW] Indymedia UK. Available from: http://www.indymedia.org.uk/en/2011/06/480322.html [Accessed 30/08/13].

Anonymousc(2011) Banks and Tesco's smashed, Bristol (UK) [WWW] Act For Freedom Now! Available from: http://actforfreedomnow.wordpress.com/2011/09/21/bank-and-tescossmashed-bristol-uk/ [Accessed 03/01/14].

Anonymous ${ }^{\mathrm{d}}$ (2014) Gross Misconduct and the guerilla massive: Poems and lunacy from Bristol [WWW] NoState325. Available from: http://325.nostate.net/?p=9754 [Accessed: 05/03/14].

Borum, Randy and Tilby, Chuck (2005) 'Anarchist direct actions: A challenge for law enforcement', Studies in Conflict \& Terrorism, 28(3), pp.201-223.

Brantingham, Paul and Brantingham, Patricia (2008) Crime pattern theory. In: Wortley, Richard and Mazerolle, Lorraine (eds.) Environmental criminology and crime analysis. Portland: Willan, pp.78-93.

Bryman, Alan (2008) Social Research Methods. Oxford: Oxford University Press.

Caplan, Bryan (2006) 'Terrorism: The relevance of the rational choice model', Public Choice, 128 (1-2), pp 91-107.

Channel 4. (2015) https://www.channel4.com/news/terrorism-which-cities-are-most-at-risk

Clarke, Roland V. (2008) Situational crime prevention. In: Wortley, Richard and Mazerolle, Lorraine (eds.) Environmental criminology and crime analysis. Portland: Willan, pp.178-194.

Clarke, Roland V. (2013) Seven Misconceptions of Situational Crime Prevention. In: Tilley, Nick (ed.) Handbook of Crime Prevention Community Safety. London: Routledge pp.39 -70.

Clarke, Roland V. and Newman, Graeme R. (2006) Outsmarting the terrorists. London: Praeger Security international. 
Cornish, Derek B. and Clarke, Roland V. (2008) The rational choice perspective. In: Wortley, Richard and Mazerolle, Lorraine (eds.) Environmental criminology and crime analysis. Portland: Willan, pp.21-47.

Coupe, Timothy and Blake, Laurence (2006) 'Daylight and darkness targeting strategies and the risks of being seen at residential burglaries', Criminology, 44(2), pp.431-464.

Diani, Mario (2005) Cities in the world: Local civil society and global issues in Britain. In: Della Porta, Donatella and Tarrow, Sidney (eds.) Transnational Protest and Global Activists. Oxford: Rowman and Littlefield, pp.45-71.

Doherty, Brian, Plows, Alexandra and Wall, Derek (2003) 'The preferred way of doing things: The British direct action movement', Parliamentary Affairs, 56, pp. 669-686.

Felson, Marcus and Boba, Rachel (2010) Crime and everyday life (4th ed.). Thousand Oaks, CA: Sage.

Field, Andy (2009) Discovering statistics using SPSS: Third edition. London: Sage.

Franks, B. (2003) 'Direct action ethic', Anarchist Studies, Volume (No. 1), pp. 13-4, [online], Available from: http://eprints.gla.ac.uk/3036/1/Direct_action_ethic.pdf [Accessed 16/08/13].

Fussey, Pete (2011) 'An economy of choice? Terrorist decision-making and criminological rational choice theories reconsidered', Security Journal, 24, pp.85-99.

Garrett, Ronnie (2004) 'Tree huggers with hand grenades?', Law enforcement technology, September, pp.88-95.

Gill, P., Marchment, Z., Corner, E., \& Bouhana, N. (2018). Terrorist Decision- Making In The Context of Risk, Attack Planning and Attack Commission. Studies in Conflict \& Terrorism, 01-24

Gordon, Uri (2007) 'Anarchism reloaded', Journal of Political Ideologies, 12(1), pp. 29-48. Gower, Patrick (2005) “Direct action”, Police Review, May, pp 18-21.

Heinze, Georg (2006) 'A comparative investigation of methods for logistic regression with separated or nearly separated data', Statistics in Medicine, 25, pp. 4216-4226.

HMIC (2012) A review of national police units which provide intelligence on criminality associated with protest, [online], Available from:

http://www.justiceinspectorates.gov.uk/hmic/publication/review-of-national-police-unitswhich-provide-intelligence-on-criminality-associated-with-protest-20120202/ [Accessed:05/10/13].

Hollis-Peel, Meghan E., Danielle M. Reynald, Maud Van Bavel, Henk Elffers, and Brandon C. Welsh. (2011). "Guardianship for crime prevention: A critical review of the literature." Crime, law and social change 56, no. 1, pp 53-70. 
Hollis, Meghan E., Marcus Felson, and Brandon C. Welsh. (2013) "The capable guardian in routine activities theory: A theoretical and conceptual reappraisal." Crime Prevention and Community Safety 15, no. 1, pp 65-79.

Hoffman, Bruce (2006) Inside terrorism. New York: Columbia University Press.

Hox, Joop J., and Hennie R. Boeije. (2005) "Data collection, primary versus secondary." pp 593-599.

Improvised Guerilla Formation (2013) Barclays bank firebombed in Bristol - statement and reflection by a FAI group [WWW] Bristol Indymedia. Available from: http://bristol.indymedia.org.uk/article/766092 [Accessed 30/08/13].

Kinna, Ruth. (2005). "A Beginner's Guide. Anarchism."

LaGrange, Teresa C. (1999) 'The Impact of Neighborhoods, Schools, and Malls on the Spatial Distribution of Property Damage', Journal of Research in Crime and Delinquency, 36, pp. 393422.

Marchment, Zoe, Noemie Bouhana and Paul Gill. (2018) Lone Actor Terrorists: A Residenceto-Crime Approach. Terrorism and Political Violence.

Morris, S. (2015) 'Bristol Activist Jailed For Two Years for Targeting Police Cars With Tyre Spikes.” The Guardian 24 February, 2015.

MI5 (2013) Domestic Extremism [WWW] Security Service MI5. Available from: http://www.mi5.gov.uk/home/the-threats/terrorism/domestic-extremism.html [Accessed 05/10/13].

Monaghan, Rachel (1999) 'Terrorism in the name of animal rights', Terrorism and Political Violence, 11(4), pp.159-169.

National Counter Terrorism Security Office (NaCTSO). 2009. Counter terrorism protective security advice for higher and further education.

Newton, Andrew D., and Kate J. Bowers. (2007) "The geography of bus shelter damage: The influence of crime, neighbourhood characteristics and land-use." Internet Journal of

Criminology

Pearl, Steve (2005) "Extreme threat: How officers should look to tackle the organised protestors", Police Review, May, pp 24-25.

Purdue, D., Diani, M. and Lindsay, I. (2004) 'Civic networks in Bristol and Glasgow', Community Development Journal, 39(3), pp. 277-288.

Roach, Jason, Ekblom, Paul and Flynn, Richard (2005) 'The conjunction of terrorist opportunity: A framework for diagnosing and preventing acts of terrorism', Security Journal, 18(3), pp. 7-25. 
Schuurman, B., Bakker, E., Gill, P., \& Bouhana, N. (2018). Lone Actor Terrorist Attack Planning and Preparation: A Data-Driven Analysis. Journal of forensic sciences, 63(4), 11911200.

Staniforth, Andrew (2009) "Dangerous liaisons: Domestic Extremists", Police Review, February, pp 28-29.

Tewksbury, Richard, and Elizabeth Ehrhardt Mustaine. (2000). "Routine activities and vandalism: A theoretical and empirical study." Journal of Crime and Justice 23, no. 1, pp 81110 .

Von Lampe, Klaus. "The application of the framework of situational crime prevention to 'organized crime'." Criminology \& Criminal Justice 11, no. 2 (2011): 145-163.

Wall, Derek (1999) Earth First! And the anti-roads movement: Radical environmentalism and comparative social movements. London: Routledge.

Welsh, Brandon C., Mark E. Mudge, and David P. Farrington. (2010) "Reconceptualizing public area surveillance and crime prevention: Security guards, place managers and defensible space." Security Journal 23, no. 4, pp 299-319.

Wilcox, Pamela, Tamara D. Madensen, and Marie Skubak Tillyer. (2007) "Guardianship in context: Implications for burglary victimization risk and prevention." Criminology 45, no. 4, pp 771-803. 
Table 1: Bivariate Analysis

\begin{tabular}{|l|l|l|l|l|}
\hline Independent Variable & DE Event & $\begin{array}{l}\text { Non-DE } \\
\text { Event }\end{array}$ & $\chi^{2}(1)=$ & $\begin{array}{l}\text { Cramer's V } \\
(\text { sig. })\end{array}$ \\
\hline $\begin{array}{l}\text { Presence of Capable } \\
\text { Guardian }\end{array}$ & $20 \%$ & $44 \%$ & $12.77^{* * *}$ & $.259(.000)$ \\
\hline Fencing & $15 \%$ & $5 \%$ & $4.74^{*}$ & $.158(.030)$ \\
\hline Lighting & $35 \%$ & $81 \%$ & $41.80^{* * *}$ & $.469(.000)$ \\
\hline CCTV & $55 \%$ & $27 \%$ & $14.70^{* * *}$ & $.278(.000)$ \\
\hline Target Visibility & $56 \%$ & $73 \%$ & $5.86^{*}$ & $.176(.015)$ \\
\hline $\begin{array}{l}\text { Commercial/Public/State } \\
\text { Building Targeted }\end{array}$ & $56 \%$ & $5 \%$ & $57.17 * * *$ & $.549(.000)$ \\
\hline $\begin{array}{l}\text { Instrument Used to Commit } \\
\text { Crime }\end{array}$ & $99 \%$ & $54 \%$ & $53.84 * * *$ & $.532(.000)$ \\
\hline
\end{tabular}

Key: $* * *=\mathrm{p}<0.001 ; * *=\mathrm{p}<0.01 ; *=\mathrm{p}<.05$, 
Table 2 - Logistic Regression Analysis

\begin{tabular}{|l|l|l|l|l|l|}
\hline Variable & $\mathbf{B}(\mathrm{SE})$ & Sig & $\mathbf{E x p}(\mathbf{B})$ & Lower & Upper \\
\hline Capable Guardian & $-.661(.551)$ & .230 & .516 & .175 & 1.520 \\
\hline Lighting & $-3.137(.709)$ & $\mathbf{. 0 0 0} * * *$ & .043 & .011 & .174 \\
\hline CCTV & & & & & \\
\hline Fencing & $1.908(.702)$ & $\mathbf{. 0 0 4} * * *$ & 6.740 & 1.848 & 24.578 \\
\hline Visible Target & $1.646(.941)$ & .080 & 5.186 & .819 & 32.819 \\
\hline Instrument & $.505(.576)$ & .380 & 1.657 & .536 & 5.123 \\
\hline Public Building & $3.929(.769)$ & $\mathbf{. 0 0 0 * *}$ & 50.877 & 11.273 & 229.625 \\
\hline Constant & $4.123(1.328)$ & $\mathbf{. 0 0 2} * *$ & 61.750 & 4.571 & 834.126 \\
\hline
\end{tabular}




\section{Figure 1: Sampling Framework}

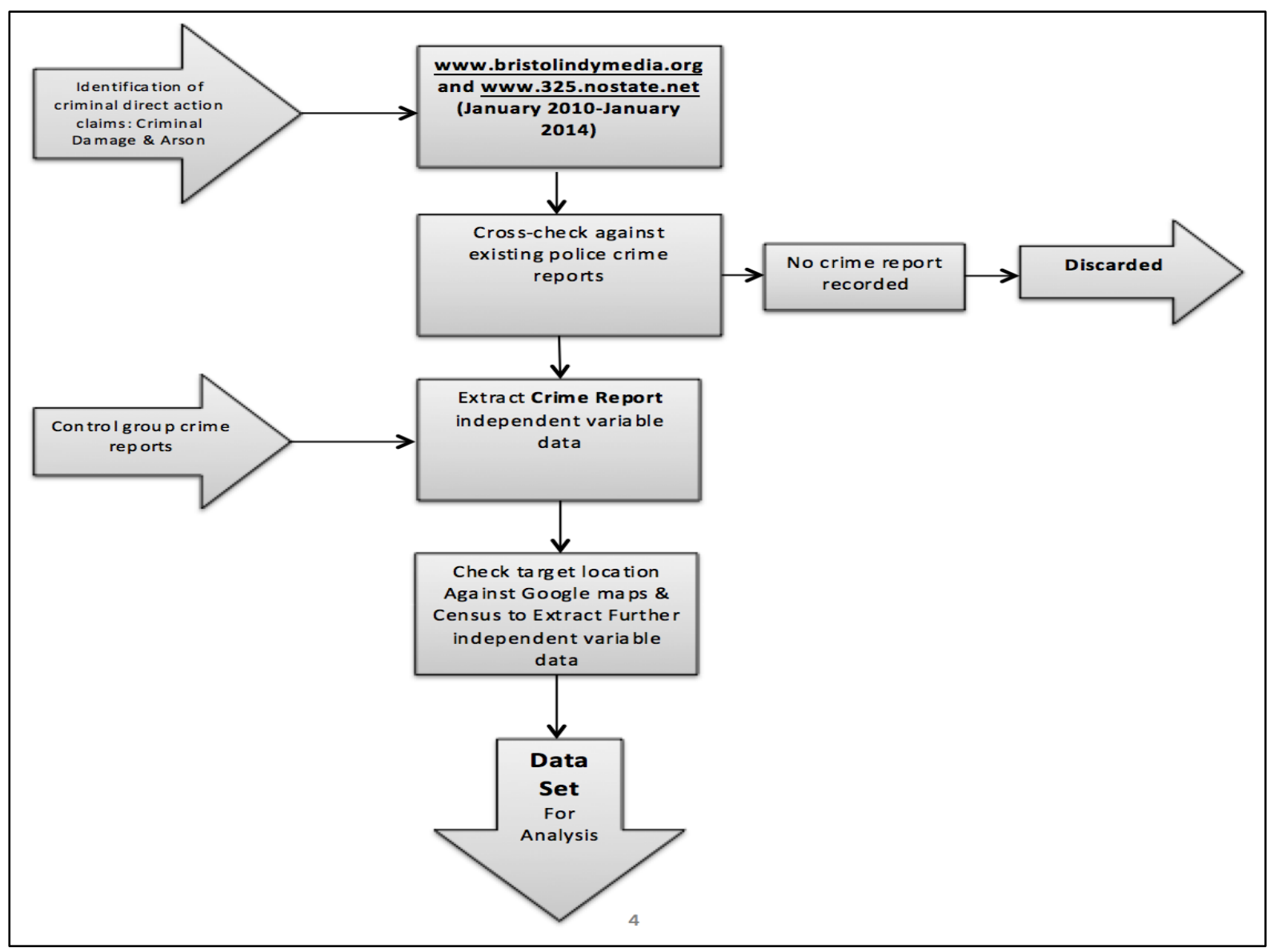

